\title{
Relation between Academic Achievement, Executive Function, Intelligence and Meta Cognition
}

\author{
Aditi Kadian ${ }^{1 *}$
}

\section{ABSTRACT}

Academic achievement or (academic) performance is the outcome of education - the extent to which a student, teacher or institution has achieved their educational goals. Academic achievement generally refers to how well a student is accomplishing his or her tasks and studies. The most well-known indicator of academic achievement is the student's 'score' for their classes and overall tenure. Many variables affect the academic achievement of the student i.e. Meta cognition, executive function, intelligence etc. The present study will investigate the relation between Meta cognition, executive function, intelligence and academic achievement. For this purpose a sample of 100 students $\left(6^{\text {th }}\right.$ to $\left.8^{\text {th }}\right)$ was selected and data was collected.

Keywords: Academic Achievement, Executive Function, Intelligence, Meta Cognition

Academic achievement or (academic) performance is the outcome of education - the extent to which a student, teacher or institution has achieved their educational goals. Academic achievement generally refers to how well a student is accomplishing his or her tasks and studies. The most well-known indicator of academic achievement is the student's 'score' for their classes and overall tenure. Academic achievement is commonly measured by examinations or continuous assessment but there is no general agreement on how it is best tested or which aspects are most important procedural knowledge such as skills or declarative knowledge such as facts. The world is becoming more and more competitive. Quality of performance has become the key factor for personal progress. Parents desire that their children climb the ladder of performance to as high a level as possible. This desire for a high level of achievement puts a lot of pressure on students, teachers, schools, and, in general, the educational system itself. In fact, it appears as if the, whole system of education revolves round the academic achievement of students, though various other outcomes are also expected from the system. Thus a lot of time and effort of the schools are used for helping students to achieve better in their scholastic endeavors. The importance of scholastic or academic achievement has raised several important questions for

\footnotetext{
${ }^{1}$ Jai Bharat High School, Nidana, Jind, Haryana, India

*Responding Author

(C) 2016 I A Kadian; licensee IJIP. This is an Open Access Research distributed under the terms of the Creative Commons Attribution License (http://creativecommons.org/licenses/by/2.0), which permits unrestricted use, distribution, and reproduction in any Medium, provided the original work is properly cited.
} 
educational researchers. What factors promote achievement in students? How far do the different factors contribute towards academic achievement? Many factors have been hypothesized and researched upon. Researchers have come out with varied results, at times complementing each other, but at times contradicting each other. A complete and comprehensive picture of academic achievement still seems to eluding the researchers. The search, therefore, continues; educational researchers all over the world are still seeking a breakthrough in elucidating this phenomenon. In view of this it will be very useful to undertake a synoptic view of the researches conducted in the field so far as this will indicate the areas on which educational researchers could concentrate most profitably.

Attempts have been made over the past years to classify the studies in this area. The credit of undertaking a pioneering work this direction goes to R.H. Dave (1968). In the third Indian Yearbook of Education he has reviewed 17 researches in the field which were carried out at M.Ed. and Ph.D. levels. Though the compilation was not exhaustive, it did indicate that the studies were undertaken to investigate into the relationship between achievement and variables like socioeconomic status, sex, intelligence and so on. Seventh Annual Survey of Education Report (Jan 2012) of rural India, released by the HRD minister, reported shows a decline in education in India. One half of the number of children in classes 3 to 5 in rural schools cannot read class first text book in their mother tongue and only 31 percent of children in classes 6 to 8 can do division. ASER shows decline in education level in India. There are many factors which influence the academic performance of the students. The government also makes plans and policies to assess the academic achievement of the students. For example Haryana Government has initiated a survey of learning levels of its students. This is being undertaken to measure the ground situation of present education system and to explore the factors affecting the scholastic achievements of the children. The survey is named as learning level outcome assessment. For this the $3^{\text {rd }}$ and $5^{\text {th }}$ standard students of Haryana government schools are being tested for four days in three subjects i.e. Hindi, English and Mathematics. Along with this the major contributory factors which significantly affect the learning level of the student, such as school infrastructure, teacher's social and academic profile and pupils' family profile will also be surveyed. This survey is being undertaken with the help of specially designed questionnaires which contain objective as well as subjective questions. For the purpose Haryana Government has taken the help of NCERT and several other NGOs active in the education spectrum. However, there are many others factors which also influence the academic performance of the students. Some are more important than others i.e. executive function, intelligence, meta cognition etc.

Longitudinal research suggests that Executive Function (EF) contributes to academic achievement rather than vice versa (Bull, Espy, \& Wiebe, 2008; Georgie \& Greenfield, 2005; Hitch, Towse, \& Hutton, 2001; Miller \& Hinshaw, 2010). Furthermore, EF has been linked to academic achievement in children of various ages with and without specific learning disabilities 
(Best, Miller, \& Jones, 2000). Performance on inhibition and working memory tasks, in particular, consistently relates to performance in mathematics and reading (Blair \& Razza, 2007). Shifting, on the other hand, does not consistently relate to academic achievement (Vander Sluis et al., 2007). Executive functions are among the most pertinent cognitive abilities for adaptive functioning, allowing for behavior that is more goal-oriented, flexible, and autonomous. As such, the measurement of executive functions is of great interest for both clinical assessment and research into multiple relevant behaviors. Given their importance, both objective and subjective tests have been developed to evaluate them.

Some authors have shown interest in meta-cognitive strategies or macro strategies which include activities that help students in their learning planning, monitoring, and evaluation. Met cognition refers to higher order thinking which involves active control over the cognitive processes engaged in learning. Activities such as planning how to approach a given learning task, monitoring comprehension, and evaluating progress toward the completion of a task are meta cognitive in nature. This higher-level cognition was given the label meta cognition by American developmental psychologist John Flavell (1979). The term meta cognition literally means cognition about cognition, or more informally, thinking about thinking. Flavell defined meta cognition as knowledge about cognition and control of cognition. For example, I am engaging in meta cognition if I notice that I am having more trouble learning A than B; or if it strikes me that I should double check C before accepting it as fact. J. H. Flavell (1976, p. 232). Andreas Demetriou, in his theory, one of the neo-Piagetian theories of cognitive development, used the term hyper cognition to refer to self-monitoring, self-representation, and self-regulation processes, which are regarded as integral components of the human mind. Meta cognition also thinks about one's own thinking process such as study skills, memory capabilities, and the ability to monitor learning. This concept needs to be explicitly taught along with content instruction. Meta cognitive knowledge is about our own cognitive processes and our understanding of how to regulate those processes to maximize learning. An association of field-dependence with the desire to plan and monitor one's own learning has been registered, as well as a greater efficiency of these processes (Abraham, 1983; Boutin \& Chinien, 1992; Liu \& Reed, 1994). In the domain of cognitive_neuroscience, meta cognitive monitoring and control has been viewed as a function of the prefrontal cortex, which receives (monitors) sensory signals from other cortical regions and through feedback loops implements control (Schwartz \& Bacon, 2008). Students with fieldindependent style maintain a greater consciousness of their learning experiences and their personal role in them (Boutin \& Chinien, 1992).

Individual differences in academic performance have been linked to differences in intelligence. Students with higher mental ability as demonstrated by IQ tests (quick learners) and those who are higher in conscientiousness (linked to effort and achievement motivation) tend to achieve highly in academic settings. (McDonald, Newton, Whetton, Cand Benefield 2001). A recent meta-analysis suggested that mental curiosity (as measured by typical intellectual engagement) 
has an important influence on academic achievement in addition to intelligence and conscientiousness. When psychologist Alfred Binet developed a test to measure the intellectual skills of French schoolchildren in 1904, he could not have possibly imagined how his research would change the world. In the last century, IQ and achievement tests have changed the face of education and employment all over the industrialized world. Given modern controversies regarding IQ testing, one might ask how Binet viewed intelligence. Binet equated intelligence with common sense. He called intelligence "judgment...good sense...the faculty of adapting one's self to circumstances." Binet also believed that intelligence is a combination of many skills - skills that are shaped heavily by the environment. His research goal was to help teachers adapt their teaching methods to the needs and abilities of individual students. Students with a weakness in math, for example, could receive special attention in this specific area.

Things changed when IQ and achievement tests were transplanted to America. Some researchers continued to believe that intelligence is a learned combination of many different skills and abilities. Others, however, assumed that intelligence is a single trait that is heavily determined by genetics. Some people further assumed that there are large ethnic or racial differences in general intelligence. A new wave of research now supports Binet's original, more progressive, assumptions. For example, researchers have shown that IQs have been steadily rising, year by year, all over the industrialized world. This historical tendency for average IQ to increase is called the Flynn effect, named after James R. Flynn. The Flynn effect has profound implications for how one thinks about IQ. For example, the Flynn effect means that Blacks today have a higher average IQ performance than Whites of 60 or 70 years ago. This difference cannot be genetic because human gene pools do not change over such short periods ( Neisser, 1998).

Identification of significant predictors of academic performance would have important implications not only for the study of learning processes, but also as tools for improving of curriculum designs, tutorial systems, and students' academic results (Miñano et. al., 2008; Musso \& Cascallar, 2009a; Zeegers, 2004). Thus, accurate prediction of student performance could have many useful applications for positive outcomes of the learning process and lead to advances in learning theory. For example, it could be helpful in identifying students at risk of low academic achievement (Musso \& Cascallar, 2009a; Ramaswami \& Bhaskaran, 2010). This prediction could serve as an early warning of future low academic performance and guide interventions that could prove beneficial for such students. Similarly, being able to understand the role of different intervening variables that influence performance for all and for each category of performance level, would be a significant contribution to improve the approach to teaching and better understanding of the learning processes. Thus, the present study attempts to delineate the contribution of some factors to academic performance of students. 


\section{Problem}

To identify the contribution of executive function, intelligence, and Meta cognition to Academic Achievement of middle school children.

\section{Objectives}

1. To identify the correlation among executive functioning, meta cognition awareness, intelligence and academic achievement.

2. To compare the students of private school on academic achievement, executive functioning, meta cognition awareness, intelligence with students of public school.

3. To identify the highest predictor of academic achievement among executive functioning intelligence and meta cognition awareness.

\section{Hypotheses:}

1. Executive function, Meta cognition awareness, intelligence would have significant correlation with academic achievement.

2. Students of private school would be higher on academic achievement, executive functioning, meta cognition awareness, intelligence rather than students of public school.

3. Intelligence would better predict academic achievement rather than executive functioning and meta cognition awareness.

\section{METHOD}

\section{Sample:}

A purposive sample of 100 students (6-8 grades) was selected on the basis of availability, such that 50 students were from private school where as other 50 students were from government school. These respondents were from both gender (male and female).

\section{Tools:}

For the purpose of the present study, following tools were used:

Raven Progressive Matrices: .Raven Progressive Matrices (Raven \& Raven 1938) was used to measure the IQ level of the students. It is a non verbal test. It consists of 60 items. These items are arranged in five sets. It is a multiple choice test. This format is designed to measure the test taker's reasoning ability or component of Spearman's g. Items are arranged in ascending order according to their difficulty level. One mark is given for every correct response. In this way raw scores are calculated. Later raw scores can be converted into percentile.

Meta cognition Awareness Inventory: It is designed by Schraw \& Dennison (1994). There is 52 questions in it. This test examines the respondent on two parts i.e. knowledge about cognition and regulation of cognition. Respondent has to tick true/false. There is one mark for each true answer. The scoring is done on eight dimensions i.e. planning, information management strategies, comprehension monitoring, debugging strategies, evaluation, declarative knowledge, procedural knowledge, and conditional knowledge. 
Executive function Index: The EFI (Spinella 2002) is a self-rating measure of executive functioning. It provides a quick, convenient measure of a person's perception of their own executive functions.. It is similar in content and structure with other self-rating executive function measures. The EFI measures executive function rather than dysfunction. It is scored so that higher scores indicate better executive functioning and vice versa. As some items indicate worse executive functioning, so their scores must be inverted before being to tolled (i.e. 1=5, $2=4,3=3,4=2,5=1$ ), while other items are scored as is. The items that must be inverted are 2,4 , $5,6,11,12,13,15,17,20,22,23,24$, as indicated by a minus sign ("-") next to each item on the printable form (see excel file, tab labelled "form"). Positively valence items, likewise have a plus sign ("+") next to them. These are only placed there for the sake of clarity, and are not printed out in the form that is given to participants.

\section{Procedure:}

Data collection was done from Govt. High School, Nidana and Jai Bharat High School, Nidana. Permission was taken from the principals. Before starting the procedure, rapport was established. General instructions related to the all three test were given to them. Special instructions that relate to test were given before each test. Participants were administered the RPM, MAI, EFI on same day. As tests took a lot of time, so small breaks were allowed. After completion, Performa was collected and scoring was done. Statically analysis was done by SPSS.

\section{RESULTS \& DISCUSSION}

The present research sought to assess the relationship among intelligence, meta cognition awareness, executive functioning and academic achievement. The data were analyzed in three sections. Firstly, we calculate the correlation between all variables. Secondly, to test for the significance of differences in between students of public and private schools, t-test was computed. lastly, to find out the predicator of academic achievement, regression analysis was done.

Table:1 showing the inter correlation matrix among the variables

\begin{tabular}{|l|l|l|l|l|l|}
\hline \multicolumn{2}{|c|}{} & total marks & EFI & RPM & MAI \\
\hline total marks & Pearson Correlation & 1 & $.875^{* *}$ & $.877^{* *}$ & $.866^{* *}$ \\
\hline EFI & Pearson Correlation & $.875^{* *}$ & 1 & $.715^{* *}$ & $.851^{* *}$ \\
\hline RPM & Pearson Correlation & $.877^{* *}$ & $.715^{* *}$ & 1 & $.822^{* *}$ \\
\hline MAI & Pearson Correlation & $.866^{* *}$ & $.851^{* *}$ & $.822^{* *}$ & 1 \\
\hline
\end{tabular}

**. Correlation is significant at the 0.01 level (2-tailed).

Results inter-correlation from table I, reveal that there is a strong positive correlation among the variables. . Intelligence shows the highest positive correlation $(r=.877 ; \mathrm{p}<.01)$.Executive functioning $(\mathrm{r}=.851 ; \mathrm{p}<.01)$ and meta cognition awareness $(\mathrm{r}=.822 ; \mathrm{p}<.01)$ also positively 
correlate with academic achievement. Thus our first hypothesis that intelligence, executive functioning, meta cognition awareness have a positive correlation with academic achievement is proved. This results means that when a student scores high in his studies, he is also high on this aspects of his personality. McDonald, Newton, Whetton, Cand Benefield (2001) also found the same results in their study.

To test the significance of differences in between students of public and private schools, $t$ test was computed.

Table 2: t-ratio for total marks, EFI, RPM, MAI between the students of public and private school.

\begin{tabular}{|c|c|c|c|c|c|c|c|}
\hline & \multicolumn{2}{|l|}{ Schools } & $\mathbf{N}$ & Mean & t- ratio & $\begin{array}{l}\text { Std. } \\
\text { Deviation }\end{array}$ & $\begin{array}{ll}\text { Std. Error } \\
\text { Mean }\end{array}$ \\
\hline \multirow{2}{*}{$\begin{array}{l}\text { total } \\
\text { marks }\end{array}$} & \multirow{2}{*}{ dimension1 } & 1.00 & 50 & 457.5200 & 7.466 & 66.54881 & 9.41142 \\
\hline & & 2.00 & 50 & 350.3800 & & 76.60764 & 10.83396 \\
\hline \multirow[t]{2}{*}{ EFI } & \multirow{2}{*}{ dimension 1} & 1.00 & 50 & 79.8400 & 3.832 & 10.39105 & 1.46952 \\
\hline & & 2.00 & 50 & 70.5800 & & \begin{tabular}{|l|}
13.56630 \\
\end{tabular} & 1.91856 \\
\hline \multirow[t]{2}{*}{ RPM } & \multirow{2}{*}{ dimension1 } & 1.00 & 50 & 35.4400 & 11.455 & 6.04460 & .85483 \\
\hline & & 2.00 & 50 & 21.6200 & & 6.02000 & .85136 \\
\hline \multirow[t]{2}{*}{ MAI } & \multirow{2}{*}{ dimension1 } & 1.00 & 50 & 35.2800 & 7.201 & 6.33436 & .89581 \\
\hline & & 2.00 & 50 & 26.5000 & & 5.84930 & .82722 \\
\hline
\end{tabular}

Table 2 shows that the mean scores of total marks of private school is 457.52 which is more than the corresponding means scores of 350.38 for public school students. The $t$ value testing the significance of mean difference in total marks of public and private school is 7.466, which is significant at 0.01 level. Same trend is found for intelligence, executive functioning, and meta cognition. Mean scores of private school students are high on each variable than public school students. Thus our second hypothesis that Students of private school would be higher on academic achievement, executive functioning, meta cognition awareness, intelligence rather than students of public school is proved. This kind of results shows that in private schools much attention is paid towards the students. On the other hand this results also strength the notion that most of the intelligent students take admissions in private schools.

(C) The International Journal of Indian Psychology, ISSN 2348-5396 (e)| ISSN: 2349-3429 (p) | 172 
To find out the predicator of academic achievement, regression analysis was done.

Table: 3 regression analysis of academic achievement with intelligence, executive functioning, and meta cognition

\begin{tabular}{|l|l|l|l|l|l|}
\hline \multicolumn{2}{|l|}{ Model } & R & R Square & $\begin{array}{l}\text { Adjusted } \\
\text { Square }\end{array}$ & $\begin{array}{l}\text { Std. Error of the } \\
\text { Estimate }\end{array}$ \\
\hline \multirow{2}{*}{ dimension0 } & 1 & $.877^{\mathrm{a}}$ & .770 & .767 & 43.12287 \\
\cline { 2 - 6 } & 2 & $.946^{\mathrm{b}}$ & .896 & .893 & 29.19739 \\
\hline
\end{tabular}

a. Predictors: (Constant), RPM

b. Predictors: (Constant), RPM, EFI

Results from table 3 shows that in stepwise regression analysis adjusted r square value for RPM is .76 where for RPM and EFI the adjusted $r$ square value is .893. This shows that intelligence has a great effect on academic achievement in comparison to executive functioning and meta cognition. Miñano et. al. (2008) Musso \& Cascallar (2009a); Zeegers, (2004) also found the same results. Thus our third hypothesis that intelligence would predict academic achievement better rather than executive functioning and meta cognition.

\section{Acknowledgments}

The author appreciates all those who participated in the study and helped to facilitate the research process.

\section{Conflict of Interests}

The author declared no conflict of interests.

\section{REFERENCES}

Abraham (2005). Exercise and Children's Intelligence, Cognition and Academic Achievement. Educational Psychology. 20 (2): 111-131.

Bangirana, P., Menk, J., John, C., Boivin, M.J., Hodges, J.S., (2013) The Association between Cognition and Academic Performance in Ugandan Children Surviving Malaria with Neurological Involvement. 8(2): 221-234.

Best, Miller, \& Jones. (2000) Counting on working memory in arithmetic problem solving. Memory and Cognition. 22: 395-410.

Blair \& Razza. (2007)The role of working memory resources in simple cognitive arithmetic. European Journal of Cognitive Psychology. 8: 73-103.

Bossaert, G; Doumen; E. Buyse; Verschueren, M., (2011). Predicting Student's Academic Achievement after the Transition to First Grade: A Two-Year Longitudinal Study. Journal of Applied Developmental Psychology. 32: 47-57.

Bratti, M., \& Staffolani, S., (2002). Student Time Allocation and Educational Production Functions. University of Ancona. Department of Economics Working Paper No. 170. 
Buckingham (2000). School size and the interpersonal side of education: An example of Race/Ethnicity and organizational context. Social Science Quarterly, 85(5):222-279.

Bull, Espy, \& Wiebe, (2008) .Working memory and children's mental addition. Journal of Experimental Child Psychology. 67:21-38.

Considine, G. \& Zappala, G. (2002). Influence of social and economic disadvantage in the academic performance of school students in Australia. Journal of Sociology, 38:159-168.

Crosnoe, R., Monica, K. J., \& Glen, H .E. (2004). School size and the interpersonal side of education: An example of Race/Ethnicity and organizational context. Social Science Quarterly, 85(5):223-245.

Eamon, M.K (2005). Social demographic, school, neighborhood, and parenting influences on academic achievement of Latino young adolescents. Journal of Youth and Adolescence, 34(2): 163-175.

Georgie \& Greenfield (2005) an overview of self-determination theory: an organistic-dialectical perspective. In Handbook of Self-Determination Research, E. L. Deci and R. M. Ryan, Eds., pp. 3-34, University of Rochester, Rochester, NY, USA .

Graetz, B. (2005). Socio-economic status in education research and policy. Journal of family and Economic Issues. 23(2):167-189.

Jacobs, C.J. (2002). Women's access to higher education in Africa: Uganda's experience. Kampala: Fountain publishers Ltd.

Jeynes, William H. (2002). Examining the effects of parental absence on the academic achievement of adolescents: the challenge of controlling for family income. Journal of family and Economic Issues. 23(2):112-145.

Machin (2006). Maternal Education and Children's Academic Achievement During Middle Childhood. Developmental Psychology .43: 1497-1512.

McDonald, A.S., Newton, P.E., Whetton, Cand Benefield, P., (2001). Aptitude testing for university entrance: a literature review. National foundation for educational research. 36, 438-448.

Miller, W.P and Birch, R.E. (2007). The influence of type of high school attended on university performance. Psychology in the Schools.32: 170-177.

Miñano et. al.(2008).Influence of social and economic disadvantage in the academic performance of school students in Australia. Journal of Sociology, 38:129-148.

Musso \& Cascallar (2003). School's influence of learning: A case of upper primary schools in Kampala \& Wakiso Districts.

Pearson, P. D., \& Johnson. S. (2006). Teaching reading comprehension. New York: Holt, Rinehart \& Winston.

Rusillo \& Arias (2004). Exercise and Children's Intelligence, Cognition and Academic Achievement. Educational Psychology. 20 (2): 111-131.

Shoenfeld ,S.(2003).Schools, Education and Social Exclusion, CASE Paper 29, Centre for Analysis of Social Exclusion, London School of Economics, London.

How to cite this article: A Kadian (2016), Relation between Academic Achievement, Executive Function, Intelligence and Meta Cognition, International Journal of Indian Psychology, Volume 3, Issue 4, No. 59, ISSN 2348-5396 (e), ISSN: 2349-3429 (p), DIP: 18.01.074/20160304, ISBN: 978-1-365-26307-1 